\title{
Editorial
}

\section{Could Arterial Stiffness Measured with the Cardio-Ankle Vascular Index be Applicable to a Caucasian Population, Beyond Race Difference?}

\author{
Kohji Shirai
}

Department of Vascular Function, Sakura Hospital, Toho University, Chiba, Japan

\section{See article vol. 22: 901-911}

Recently, Gomez-Sanchez et al. published an important paper ${ }^{1)}$. As this paper describes, measuring arterial stiffness using non-invasive methods as a marker of the degree of arteriosclerosis and a predictor of cardiovascular events, is becoming popular. However, pulse wave velocity (PWV), which has been used as an indicator of arterial stiffness for last 40 years, and has contributed much in this field, depends inherently on blood pressure at the time of measurement. The Cardio-Ankle Vascular Index (CAVI) was developed in Japan in order to be independent of blood pressure at measuring time. More than 260 papers on the subject of CAVI have been published to date, but most of these studies were performed in Asian populations. Gomez-Sanchez et al's paper looks at CAVI in Caucasian adults, and shows positive correlations with cfPWV, baPWV, mean and maximum Intima-Media thickness (IMT), cardiovascular risk (Framingham D'Agostino), and the systemic coronary risk evaluation scale. These results suggest that CAVI reflects the degree of systemic arteriosclerosis in Caucasian adults, too. As for its ability to predict carotid atherosclerosis, CAVI showed significance in an ROC analysis. These results are consistent with previous studies in a Japanese population (Ref 37,40 in reference 1). Therefore, the authors concluded that CAVI, as an index of arterial stiffness, is also applicable for assessment of systemic arteriosclerosis in a Caucasian population.

Furthermore, Schillaci ${ }^{2)}$ reported that a high CAVI value is associated with inappropriately high left ventricular mass and low midwall systolic function. As a marker of arterial diastolic-to-systolic stiffening,

Address for correspondence: Kohji Shirai, Seijinkai Mihama Hospital, 1-1-5, Utase, Mihama-ku, Chiba, 261-0013, Japan E-mail: kshira@kb3.so-net.ne.jp

Received: June 30, 2015

Accepted for publication: July 2, 2015
CAVI may have a relationship with left ventricular structure and function which is independent of blood pressure levels.

These papers indicate that CAVI could be applicable to Caucasians in the field of evaluating arteriosclerosis, and also in the field of study of cardiovascular interaction, beyond race difference.

\section{COI}

The author is a visiting professor of the department of vascular function endowed by Fukuda Denshi Co. Ltd., in Toho University, but have no patent, and have nothing to declare.

\section{References}

1) Gomez-Sanchez L, Garcia-Ortiz L, Maria C PatinoAlonso MC, Recio-Rodriguez JI, Frontera G, Ramos R, Marti R, Agudo-Conde C, Rodriguez-Sanchez E, Maderuelo-Fernandez JA and Gomez-Marcos MA for the MARK Group9: The Association Between the Cardioankle Vascular Index and Other Parameters of Vascular Structure and Function in Caucasian Adults: MARK Study. Atheroscler Thromb, 2015; 22: 901-911

2) Schillaci G, Battista F, Settimi L, Anastasio F, Pucci G, Cardio-Ankle Vascular Index and subclinical heart disease. Hypertens Res, 2015; 38: 68-73 